\title{
AUMC Dosing to Last Concentration Normalized by Dose
}

National Cancer Institute

\section{Source}

National Cancer Institute. AUMC Dosing to Last Concentration Normalized by Dose. NCI

Thesaurus. Code C92327.

The area under the moment curve (AUMC) from the time of dosing to the last measurable concentration divided by the dose. 